\title{
Estimating Influenza-associated Mortality in Korea: The 2009-2016 Seasons
}

\author{
Kwan Hong, Sangho Sohn, Byung Chul Chun \\ Department of Preventive Medicine, Korea University College of Medicine, Seoul, Korea
}

Objectives: Estimating influenza-associated mortality is important since seasonal influenza affects persons of all ages, causing severe illness or death. This study aimed to estimate influenza-associated mortality, considering both periodic changes and age-specific mortality by influenza subtypes.

Methods: Using the Microdata Integrated Service from Statistics Korea, we collected weekly mortality data including cause of death. Laboratory surveillance data of respiratory viruses from 2009 to 2016 were obtained from the Korea Centers for Disease Control and Prevention. After adjusting for the annual age-specific population size, we used a negative binomial regression model by age group and influenza subtype.

Results: Overall, 1859890 deaths were observed and the average rate of influenza virus positivity was $14.7 \%$ (standard deviation [SD], 5.8), with the following subtype distribution: $A(H 1 N 1), 5.0 \%$ (SD, 5.8); $A(H 3 N 2), 4.4 \%$ (SD, 3.4); and B, 5.3\% (SD, 3.7). As a result, among individuals under 65 years old, 6774 (0.51\%) all-cause deaths, 2521 (3.05\%) respiratory or circulatory deaths, and 1048 (18.23\%) influenza or pneumonia deaths were estimated. Among those 65 years of age or older, 30414 (2.27\%) all-cause deaths, 16411 (3.42\%) respiratory or circulatory deaths, and 4906 (6.87\%) influenza or pneumonia deaths were estimated. Influenza A(H3N2) virus was the major contributor to influenza-associated all-cause and respiratory or circulatory deaths in both age groups. However, influenza A(H1N1) virus-associated influenza or pneumonia deaths were more common in those under 65 years old.

Conclusions: Influenza-associated mortality was substantial during this period, especially in the elderly. By subtype, influenza A(H3N2) virus made the largest contribution to influenza-associated mortality.

Key words: Influenza, Cost of illness, Mortality, Aged, Korea

\section{INTRODUCTION}

Influenza is a common acute respiratory disease caused by influenza virus. Although influenza is frequently confused with

Received: June 17, 2019 Accepted: August 13, 2019

Corresponding author: Byung Chul Chun, MD, PhD Department of Preventive Medicine, Korea University College of Medicine, 73 Goryeodae-ro, Seongbuk-gu, Seoul 02841, Korea E-mail: chun@korea.ac.kr

This is an Open Access article distributed under the terms of the Creative Commons Attribution Non-Commercial License (http://creativecommons.org/licenses/bync/4.0/) which permits unrestricted non-commercial use, distribution, and reproduction in any medium, provided the original work is properly cited. the common cold, some individuals with influenza can become severely ill, to the point of hospitalization or even death. According to estimates of the World Health Organization, $5-10 \%$ of adults and $20-30 \%$ of children are infected by the influenza virus every year [1-3]. Therefore, measuring the disease burden of seasonal influenza is of major interest among infection epidemiologists [4-6].

A simple way to measure the disease burden is to estimate the mortality of influenza by comparing the mortality rate to the rate of influenza virus positivity. However, because of the seasonality of influenza virus and the annual variability of subtypes that cause epidemics [7], it is necessary to include com- 
plicated calculations on time and the positivity rate of each virus subtype to obtain accurate estimates of influenza-associated mortality. Furthermore, when we count only people who die directly from influenza, we cannot estimate the substantial impact that influenza virus may exert by inducing severe complications that lead to death $[7,8]$. Additionally, we need to explore various causes of death when estimating influenza-associated deaths because records for mortality may not directly include information about viral infection. Therefore, few studies have considered all these factors when measuring the disease burden of influenza. This study aimed to estimate influenza-associated deaths considering influenza type, patients' age, and various causes of death, and to explore differences in influenza severity by age group through these results. We used a negative binomial regression model for the comprehensive estimation, following previous studies [9-12].

\section{METHODS}

\section{Data Sources and Measures}

Mortality data were obtained from 2009 through 2016 for all deaths in Korea. We extracted age-specific mortality from the Microdata Integrated System (MDIS) [13], generated by Statistics Korea. The causes of death were coded by the International Statistical Classification of Diseases and Related Health Problems 10th revision in this dataset and included demographic features such as age, sex, and residence. We constructed three different models by cause of death: all-cause deaths, respiratory (diseases of the respiratory system, J00J99) or circulatory (diseases of the circulatory system, 100-199) deaths, and influenza or pneumonia (influenza and pneumonia, J09-J18) deaths. We also selected other chronic causes of deaths such as cancer (neoplasms, C00-D48) to compare the results. Age-specific weekly deaths were divided by age-specific mid-year population estimates, which were also obtained from the MDIS. The weekly age-specific mortality rate was used as a predictive variable.

The Korea Centers for Disease Control and Prevention (KCDC) provided influenza virus surveillance data through the Korea Influenza and Respiratory Viruses Surveillance System (KINRESS) [14]. Thirty-six to 90 representative institutes reported tested and positive samples for the following subtypes of influenza virus: influenza $A(H 1 N 1)$, influenza $A(H 3 N 2)$, and influenza $B$ virus. Since the KCDC started separate monitoring of each influenza virus type in 2009, we used data from 2009 to 2016 in our models. Since the influenza surveillance system is organized by season globally, we structured each season to extend from the 36th week of one year to the 35th week of the next year.

\section{Statistical Analysis}

The model included a total of 7 seasons, from 2009 to 2016, including the 2009 H1N1 pandemic. We used negative binomial regression models for the weekly age-specific mortality data. Various statistical methods have been developed for estimating influenza-associated deaths [15-30], but there is no single way to estimate the exact scale of deaths. Poisson regression analysis is broadly accepted as the predominant estimation method. However, negative binomial regression is also commonly used for modeling count data, especially when there is a suspicion of overdispersion. Since the Poisson distribution does not allow greater variability, the distribution of age-specific deaths and the positivity rate of each influenza virus in this study needed additional free parameters for model fitness. Therefore, to estimate influenza-associated deaths in 2009-2016, we used a negative binomial regression model [31] considering influenza subtypes, age, and various causes of death. An additional process of checking the model assumptions and the goodness-of-fit was performed. Mortality data were transformed into weekly deaths and divided into 2 age groups: under 65 years old and 65 years or older. To consider linear and non-linear time trends, we included these factors as covariates and the age-specific population as the offset. The prediction model can be expressed as:

$$
\begin{array}{r}
\mathrm{Y}(i)=\alpha \exp \left\{\beta_{0}+\beta_{1}\left[\mathrm{t}_{i}\right]+\beta_{2}\left[\mathrm{t}_{i}^{2}\right]+\beta_{3}\left[t_{i}^{3}\right]+\beta_{4}\left[\frac{\cos 2 \mathrm{t}_{i} \pi}{52}\right]+\right. \\
\left.\beta_{5}\left[\frac{\cos 2 \mathrm{t}_{i} \pi}{52}\right]+\beta_{6}[\mathrm{~A}(\mathrm{H} 1 \mathrm{~N} 1)]+\beta_{7}[\mathrm{~A}(\mathrm{H} 3 \mathrm{~N} 2)]+\beta_{8}[\mathrm{~B}]\right\}
\end{array}
$$

where $Y$ represents the predicted number of deaths, $\alpha$ is the offset term for the age-specific population, and $\beta_{6}$ through $\beta_{8}$ represent the estimated coefficient for each viral subtype. After predicting age-specific mortality by cause of death, we calculated viral subtype-specific deaths as the count data using this model. The total number of influenza-associated deaths was expressed as the sum of the count for each viral subtype. To deal with weekly variance and autocorrelation, the DurbinWatson test was performed and the Akaike information criterion was compared. Finally, we inserted a 1-week lag for mortality in each model. All statistical analyses were conducted in R version 3.4.0 (https://cran.r-project.org/bin/windows/base/ old/3.4.0/). 
Table 1. Annual number of deaths for the 2009-2010 through 2015-2016 seasons ${ }^{1}$

\begin{tabular}{|c|c|c|c|}
\hline Season & $<65 y$ & $\geq 65 y$ & Total \\
\hline \multicolumn{4}{|c|}{ All-cause deaths } \\
\hline $2009-2010$ & 76153 & 173336 & 249489 \\
\hline 2010-2011 & 77193 & 184243 & 261436 \\
\hline 2011-2012 & 75484 & 191777 & 267261 \\
\hline 2012-2013 & 73569 & 193172 & 266741 \\
\hline 2013-2014 & 72091 & 193816 & 265907 \\
\hline 2014-2015 & 70824 & 204065 & 274889 \\
\hline 2015-2016 & 69068 & 205099 & 274167 \\
\hline Total & 514382 & 1345508 & 1859890 \\
\hline \multicolumn{4}{|c|}{ Respiratory or circulatory deaths } \\
\hline 2009-2010 & 11904 & 60173 & 72077 \\
\hline 2010-2011 & 12187 & 66130 & 78317 \\
\hline 2011-2012 & 11862 & 69631 & 81493 \\
\hline 2012-2013 & 11850 & 68317 & 80167 \\
\hline 2013-2014 & 11593 & 69289 & 80882 \\
\hline $2014-2015$ & 11905 & 74365 & 86270 \\
\hline 2015-2016 & 11930 & 75339 & 87269 \\
\hline Total & 83231 & 483244 & 566475 \\
\hline \multicolumn{4}{|c|}{ Influenza or pneumonia deaths } \\
\hline 2009-2010 & 567 & 6240 & 6807 \\
\hline $2010-2011$ & 723 & 7932 & 8655 \\
\hline 2011-2012 & 721 & 9498 & 10219 \\
\hline 2012-2013 & 788 & 9986 & 10774 \\
\hline 2013-2014 & 825 & 10847 & 11672 \\
\hline 2014-2015 & 980 & 13258 & 14238 \\
\hline 2015-2016 & 1198 & 14287 & 15485 \\
\hline Total & 5802 & 72048 & 77850 \\
\hline
\end{tabular}

${ }^{1} T$ The annual number of deaths was extracted from the Microdata Integrated System, generated from Statistics Korea.

\section{Ethics Statement}

All data analyzed in this study are available from each organization with permission. Since no personal data were collected or stored, there was no personal information. Code for reanalysis is available from the first author upon request.

\section{RESULTS}

From the 2009-2010 season through the 2015-2016 season, 1859890 all-cause deaths, 566475 underlying respiratory or circulatory deaths, and 77850 underlying influenza or pneumonia deaths were observed (Table 1). Deaths among those at least 65 years of age accounted for $72.3 \%$ (all-cause deaths), $85.3 \%$ (respiratory or circulatory deaths), and $92.5 \%$ (influenza
Table 2. Annual positivity rates of influenza virus from the 2009-2010 through 2015-2016 seasons ${ }^{1}$

\begin{tabular}{|c|c|c|c|c|c|}
\hline \multirow{2}{*}{ Season } & \multicolumn{2}{|c|}{ Influenza A virus } & \multirow{2}{*}{$\begin{array}{c}\text { Influenza } \\
\text { B virus }\end{array}$} & \multirow{2}{*}{$\begin{array}{c}\text { All } \\
\text { influenza } \\
\text { viruses }\end{array}$} & \multirow{2}{*}{$\begin{array}{c}\text { All } \\
\text { respiratory } \\
\text { viruses }\end{array}$} \\
\hline & H1N1 & H3N2 & & & \\
\hline $2009-2010$ & 17.0 & 0.1 & 8.6 & 25.7 & 54.3 \\
\hline 2010-2011 & 7.2 & 2.6 & 0.2 & 10.0 & 42.2 \\
\hline 2011-2012 & 0.0 & 9.3 & 9.0 & 18.3 & 59.1 \\
\hline 2012-2013 & 1.9 & 6.9 & 0.6 & 9.4 & 58.7 \\
\hline 2013-2014 & 2.5 & 4.7 & 8.5 & 15.8 & 55.7 \\
\hline 2014-2015 & 1.3 & 6.3 & 4.6 & 12.2 & 50.3 \\
\hline 2015-2016 & 5.2 & 0.5 & 5.4 & 11.2 & 55.1 \\
\hline Mean $\pm S D$ & $5.0 \pm 5.8$ & $4.4 \pm 3.4$ & $5.3 \pm 3.7$ & $14.6 \pm 5.8$ & $53.6 \pm 5.8$ \\
\hline
\end{tabular}

Values are presented as \%.

SD, standard deviation.

${ }^{1} T$ The annual positivity rates of influenza virus were provided by the Korea Influenza and Respiratory Viruses Surveillance System generated by the Korea Centers for Disease Control and Prevention.

or pneumonia deaths) of deaths.

In the respiratory virus surveillance data, an average of $14.6 \%$ of specimens tested positive for influenza virus, with the following subtype distribution: influenza $A(\mathrm{H} 1 \mathrm{~N} 1)$ virus, $5.0 \%$; influenza $A(H 3 N 2)$ virus, 4.3\%; and influenza B virus, 5.3\% (Table 2). Influenza $A(\mathrm{H} 1 \mathrm{~N} 1)$ virus was the major cause of epidemics in the 2009-2010 and 2010-2011 seasons, while influenza A(H3N2) virus was the major cause of epidemics in the 2011-2012, 20122013 and 2014-2015 seasons. Influenza B virus was the main cause of the epidemic in the 2013-2014 season. In the 20152016 season, both influenza $A(H 1 N 1)$ and influenza $B$ virus were epidemic.

The overall estimated influenza-associated all-cause deaths were 5313 per year (2.02\% of all-cause deaths, 10.59 per 100000 population). In particular, the population 65 years of age or older made the largest contribution to this mortality (2.28\% of all-cause deaths among those at least 65 years old, 74.12 per 100000 population). The estimated influenza-associated mortality figures by age group are summarized in Table 3 and Figure 1. Of the all-cause deaths, $6774(0.51 \%)$ deaths in those under 65 years old and 30414 deaths (2.27\%) in those at least 65 years old were estimated to be influenza-associated deaths. While influenza $A(H 3 N 2)$ and influenza $B$ virus contributed to deaths in the younger population (under 65 years old) at a similar rate $(0.50 \%$ and $0.48 \%$ of all-cause deaths each), influenza $A(H 3 N 2)$ virus made the largest contribution of the 3 virus subtypes to deaths in the older population (at least 65 years old, 1.50\%). In total, 2521 (3.05\%) and 16411 (3.42\%) re- 
Table 3. Estimated influenza-associated deaths by the cause of death, the type of influenza virus, and age ${ }^{1}$

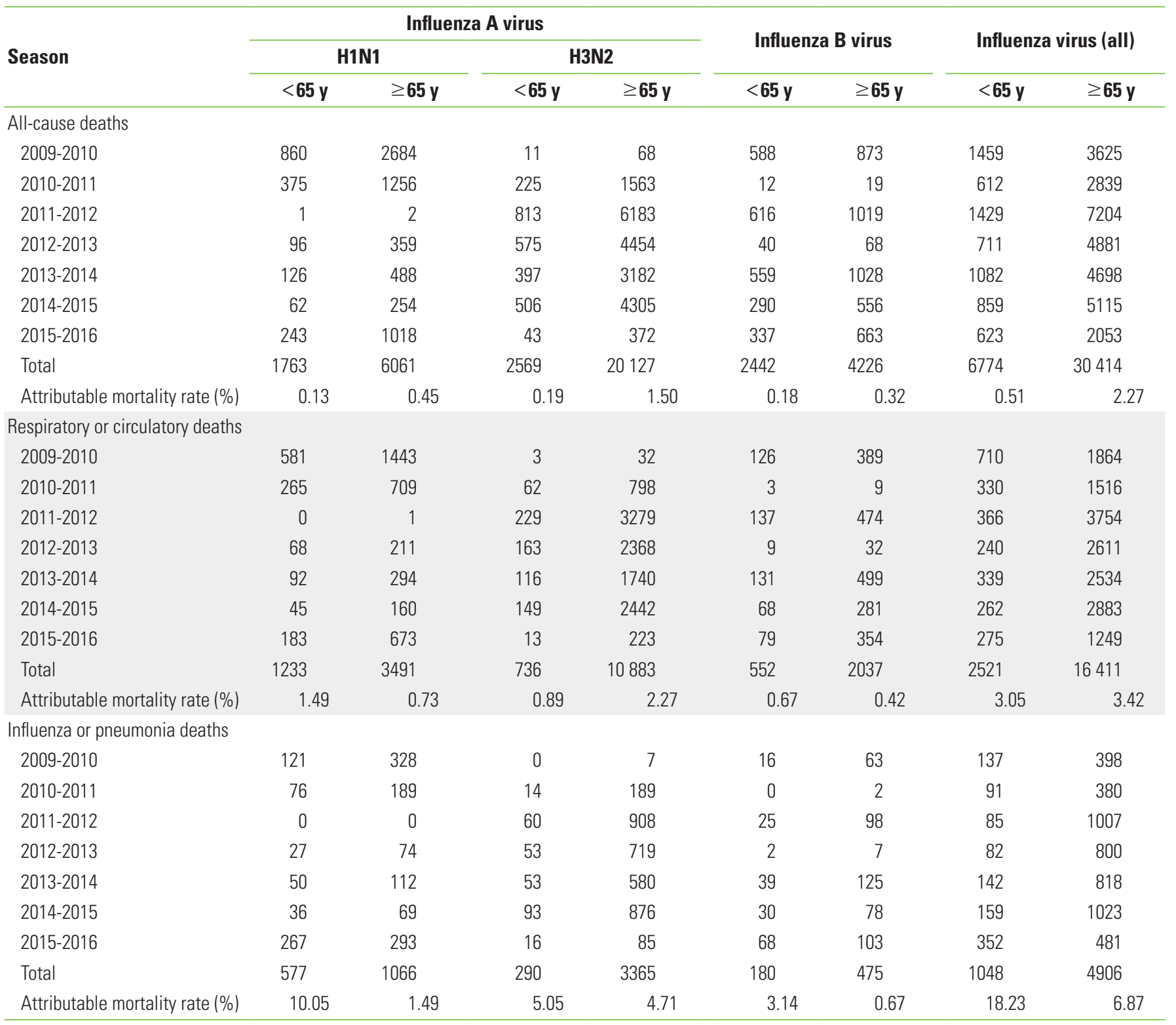

${ }^{1}$ Negative binomial regression was used for each estimate of influenza-associated deaths shown in this table.

spiratory or circulatory deaths were estimated as influenza-associated deaths in the age groups of under 65 years and 65 years or older, respectively. The overall influenza-associated respiratory or circulatory deaths were not significantly different by age group. Similarly to all-cause deaths, influenza $A(H 3 N 2)$ virus made the largest contribution to respiratory or circulatory deaths among those at least 65 years old (2.27\%). Furthermore, 1048 (18.23\%) and 4906 (6.87\%) influenza or pneumonia deaths were estimated to have occurred in the age groups of under 65 years and 65 years or older, respectively, and $10.05 \%$ of the influenza or pneumonia deaths in in- dividuals under 65 years old were due to influenza $A(\mathrm{H} 1 \mathrm{~N} 1)$ virus. In addition to season, age group and the cause of death contributed to differences in estimated deaths by influenza subtype. We only considered 3 causes of death and 3 influenza subtypes since no other causes of deaths or respiratory viruses were fitted to our model.

\section{DISCUSSION}

There were approximately 5313 influenza-associated deaths per year (10.59 per 100000 people, 74.12 per 100000 people 


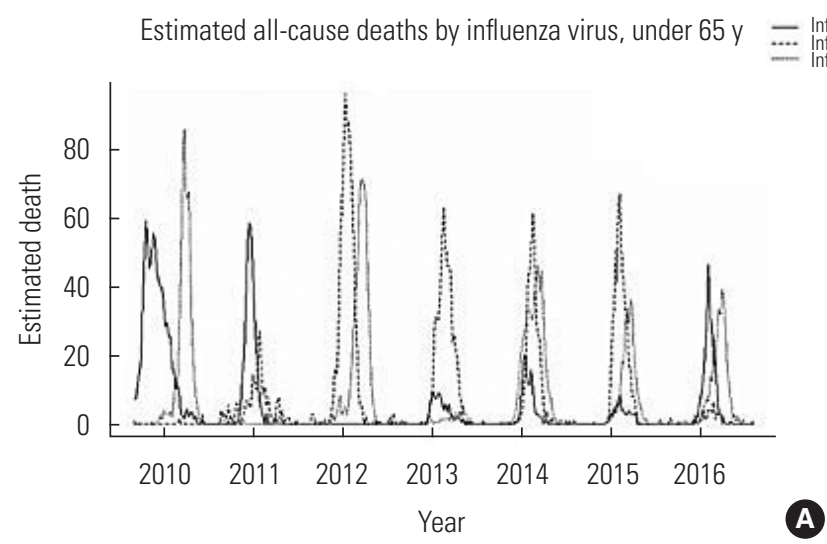

Estimated respiratory or circulatory deaths by influenza virus, under 65 y

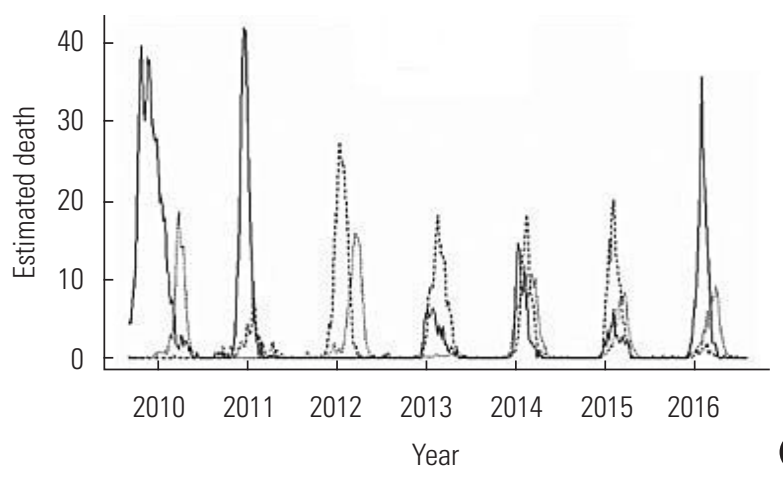

Estimated influenza or pneumonia deaths by influenza virus, under 65 y

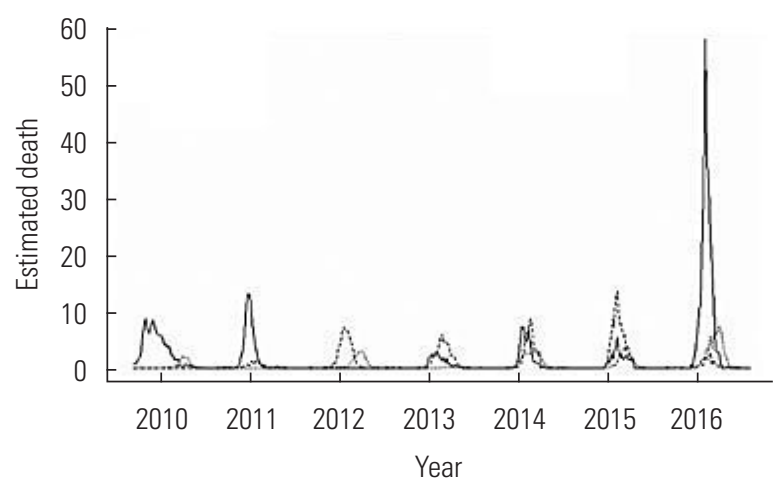

Estimated all-cause deaths by influenza virus, over $65 \mathrm{y}$

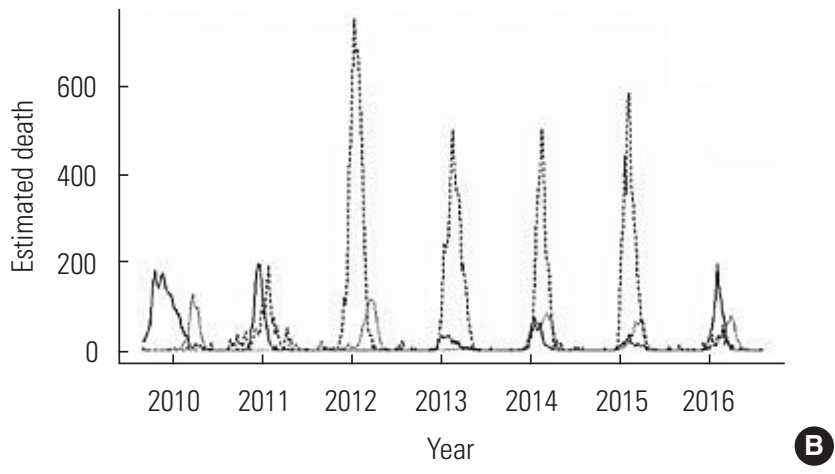

Estimated respiratory or circulatory deaths by influenza virus, over 65 y

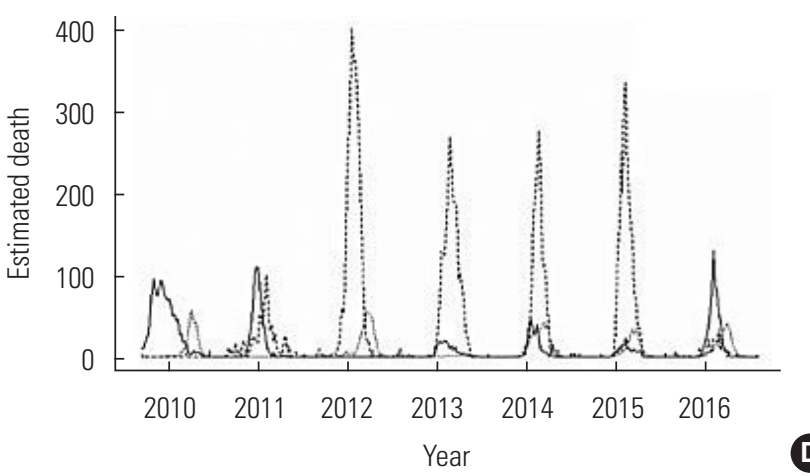

Estimated influenza or pneumonia deaths by influenza virus, over 65 y

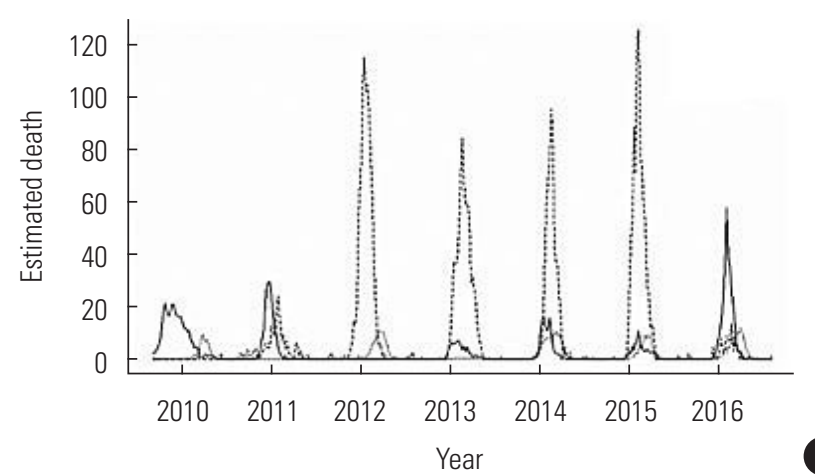

Figure 1. Estimated influenza-associated deaths per 100000 people by influenza virus type and age. A, C and E shows estimated all-cause, respiratory or circulatory, and influenza or pneumonia deaths by influenza virus in under 65 years old group, respectively. B, D and F shows estimated all-cause, respiratory or circulatory, and influenza or pneumonia deaths by influenza virus in over 65 years old group, respectively. All estimated deaths are visualized by weekly estimated data.

above 65 years old). This is the first study, to our knowledge, to estimate age-specific influenza-associated deaths in Korea using a negative binomial regression model and considering lag time and model fit. By adding the estimated mortality of each influenza subtype, we were able to apply the model more accurately. We also considered other respiratory viruses as covariates in the model, but they were excluded from the final model due to statistical non-significance. Moreover, we classified the population by age group and evaluated the suitability of the model, making it possible to estimate excess mortality by age group.

The results of this study can be compared to those of a prior study that estimated 2900 influenza-associated deaths per year in Korea [23]. Park et al. [23] used multiple linear models 
to estimate the excess mortality rate caused by influenza from 2003 through 2013. However, since it is inappropriate to assume fixed fatality among viral subtypes and age groups, and considering that death is a rare and non-negative event, a count data model might be more persuasive than a linear model for estimating influenza-associated deaths. Furthermore, the KCDC reorganized the respiratory virus surveillance system, KINRESS, in 2006, changing the institutions to be monitored by specifying the percentage of target organizations in each region. They also changed the types of respiratory viruses to be monitored, and the laboratory method for detecting positivity. Therefore, influenza positivity rates before and after 2006 are non-comparable. Additionally, the results of this study are consistent with those reported in studies from other countries $[5,16,24,26,28,29]$, most of which reported 10 or more estimated deaths per 100000 people, with recent studies showing much higher numbers of estimated deaths among the elderly.

In our analysis of estimated influenza-associated deaths by type of influenza, influenza A(H3N2) virus caused the most excess mortality, accounting for $65.8 \%$ of influenza-associated all-cause deaths. This is a meaningful point to focus on because this study included the 2009-2010 season, when influenza $A(H 1 N 1)$ virus became pandemic worldwide. Based on this fact, it can be inferred that the infectivity of influenza $A(H 1 N 1)$ virus was high, but the mortality rate was low, or that the later influenza viruses' mortality rate was higher than that of influenza $A(\mathrm{H} 1 \mathrm{~N} 1)$ virus. Regardless of the study period, a higher mortality rate of influenza $A(\mathrm{H} 3 \mathrm{~N} 2)$ virus has also been proven in other countries, perhaps because of this subtype's severity in vulnerable populations [8,23,31-34].

Another noteworthy finding of this study is the difference in the proportion of deaths attributable to different influenza subtypes between age groups. According to estimates of influenza-associated mortality, older individuals (65 years or older) were more vulnerable to influenza $A(H 3 N 2)$ virus. Considering that the deaths of individuals 65 years of age and older account for $85.3 \%$ of respiratory or circulatory deaths, the proportion of estimated influenza-associated respiratory or circulatory deaths in the older population is not negligible. Since the mortality data were extracted from death certificates, influenza or pneumonia deaths may have been over-estimated, especially in the 2009-2010 pandemic season. Furthermore, it cannot be guaranteed that other chronic causes of deaths made a constant contribution to weekly all-cause deaths. Therefore, as supported by previous studies $[8,15,35,36]$, estimated allcause deaths or influenza or pneumonia deaths could have been overestimated or underestimated. Therefore, it can be assumed that respiratory or circulatory deaths provide the most accurate estimate, compared to the other two types of estimates, in the older population.

There are several limitations of this study. The younger age group could not be subdivided into more age groups since we used weekly mortality data for the estimation, so that there were many 0 cells in the under- 15 age group. This could lead to inaccurate estimation when using a negative binomial regression model as the estimation method. Therefore, we estimated excess mortality in children and adults under 65 years of age within a single group. Fortunately, this methodological choice could only lead to underestimation of influenza-associated mortality in young adults because influenza or pneumonia deaths and respiratory or circulatory deaths occur more frequently in adults than children. Secondly, since we only used respiratory virus surveillance data for the analysis, it was not possible to consider the effects of other viral or bacterial infections in a particular week. If another infectious disease were epidemic during these seasons, it could have caused an overestimation, but there were no other life-threatening pandemic infectious diseases in this period. Finally, mortality data can have inherent uncertainty because if cause-of-death certificates are filled out at a busy moment, doctors may ignore less important or indirect causes. For this reason, respiratory or circulatory deaths may be more accurate for estimating actual influenza-associated deaths.

The high overall rate of influenza-associated deaths indicates that the burden of influenza is never light, and as noticed in the USA [37] and Europe [38], we may use surveillance data for calculating influenza-associated deaths in real time for the management of high-risk groups in each epidemic. The difference in the severity of each virus type in specific age groups also has important implications. Among the 3 types of estimated deaths in this study, the older (65 years and above) population had higher mortality in all-cause deaths or respiratory or circulatory deaths, particularly with influenza $A(H 3 N 2)$ virus. However, the younger (under 65 years) population had a higher mortality due to influenza $\mathrm{A}(\mathrm{H} 1 \mathrm{N1})$ virus, except for all-cause deaths. Additionally, influenza B virus should be considered more cautiously in them than in the elderly. Further studies are needed to explain this variance in influenza epidemics. 


\section{CONFLICT OF INTEREST}

The authors have no conflicts of interest associated with the material presented in this paper.

\section{ACKNOWLEDGEMENTS}

None.

\section{AUTHOR CONTRIBUTIONS}

Conceptualization: KH, BCC. Data curation: KH, BCC, SS. Formal analysis: KH. Funding acquisition: None. Methodology: $\mathrm{KH}, \mathrm{BCC}$, SS. Project administration: BCC. Visualization: KH. Writing - original draft: $\mathrm{KH}, \mathrm{BCC}$, SS. Writing - review \& editing: $\mathrm{KH}, \mathrm{BCC}, \mathrm{SS}$.

\section{ORCID}

Kwan Hong https://orcid.org/0000-0002-5083-8026

Sangho Sohn https://orcid.org/0000-0003-2736-3461

Byung Chul Chun https://orcid.org/0000-0001-6576-8916

\section{REFERENCES}

1. World Health Organization. Influenza (seasonal); 2018 [cited 2019 Jan 22]. Available from: https://www.who.int/news-room/ fact-sheets/detail/influenza-(seasonal).

2. Nair H, Brooks WA, Katz M, Roca A, Berkley JA, Madhi SA, et al. Global burden of respiratory infections due to seasonal influenza in young children: a systematic review and meta-analysis. Lancet 2011;378(9807):1917-1930.

3. van Asten $L$, van den Wijngaard C, van Pelt W, van de Kassteele J, Meijer A, van der Hoek W, et al. Mortality attributable to 9 common infections: significant effect of influenza $A$, respiratory syncytial virus, influenza $B$, norovirus, and parainfluenza in elderly persons. J Infect Dis 2012;206(5):628-639.

4. Molinari NA, Ortega-Sanchez IR, Messonnier ML, Thompson WW, Wortley PM, Weintraub E, et al. The annual impact of seasonal influenza in the US: measuring disease burden and costs. Vaccine 2007;25(27):5086-5096.

5. Nielsen J, Vestergaard LS, Richter L, Schmid D, Bustos N, Asikainen $\mathrm{T}$, et al. European all-cause excess and influenza-attributable mortality in the 2017/18 season: should the burden of influenza B be reconsidered? Clin Microbiol Infect 2019. doi: https://doi.org/10.1016/j.cmi.2019.02.011.

6. Paules $\mathrm{Cl}$, Sullivan SG, Subbarao K, Fauci AS. Chasing seasonal influenza - the need for a universal influenza vaccine. N Engl J Med 2018;378(1):7-9.

7. Thompson WW, Comanor L, Shay DK. Epidemiology of seasonal influenza: use of surveillance data and statistical models to estimate the burden of disease. J Infect Dis 2006;194 Suppl 2: S82-S91.

8. Thompson WW, Shay DK, Weintraub E, Brammer L, Cox N, Anderson $\mathrm{L}$, et al. Mortality associated with influenza and respiratory syncytial virus in the United States. JAMA 2003;289(2): 179-186.

9. Wang H, Fu C, Li K, Lu J, Chen Y, Lu E, et al. Influenza associated mortality in Southern China, 2010-2012. Vaccine 2014;32(8): 973-978.

10. Nguyen AM, Noymer A. Influenza mortality in the United States, 2009 pandemic: burden, timing and age distribution. PLoS One 2013;8(5):e64198.

11. Feng L, Shay DK, Jiang Y, Zhou H, Chen X, Zheng Y, et al. Influenza-associated mortality in temperate and subtropical Chinese cities, 2003-2008. Bull World Health Organ 2012;90(4): 279-288B.

12. Chow A, Ma S, Ling AE, Chew SK. Influenza-associated deaths in tropical Singapore. Emerg Infect Dis 2006;12(1):114-121.

13. Statistics Korea. Microdata integrated service [cited 2019 Jun 17]. Available from: https://mdis.kostat.go.kr/mypage/extract/ viewMyExtractDetail.do?curMenuNo=UI_POR_P1068\&procP cdtld= PROC0000000000190368 (Korean).

14. Korea Centers for Disease Control and Prevention. Influenza weekly/annual report [cited 2019 Jun 17]. Available from: http:// www.cdc.go.kr/npt/biz/npp/iss/influenzaStatisticsMain.do (Korean).

15. Nguyen JL, Yang W, Ito K, Matte TD, Shaman J, Kinney PL. Seasonal influenza infections and cardiovascular disease mortality. JAMA Cardiol 2016;1(3):274-281.

16. Thompson WW, Weintraub E, Dhankhar P, Cheng PY, Brammer $\mathrm{L}$, Meltzer Ml, et al. Estimates of US influenza-associated deaths made using four different methods. Influenza Other Respir Viruses 2009;3(1):37-49.

17. Thompson WW, Ridenhour BL, Barile JP, Shay DK. Time-series analyses of count data to estimate the burden of seasonal infectious diseases. Epidemiology 2012;23(6):839-842.

18. Mullooly JP, Bridges CB, Thompson WW, Chen J, Weintraub E, Jackson LA, et al. Influenza- and RSV-associated hospitalizations among adults. Vaccine 2007;25(5):846-855. 
19. O'Brien MA, Uyeki TM, Shay DK, Thompson WW, Kleinman K, McAdam A, et al. Incidence of outpatient visits and hospitalizations related to influenza in infants and young children. Pediatrics 2004;113(3 Pt 1):585-593.

20. Izurieta HS, Thompson WW, Kramarz P, Shay DK, Davis RL, DeStefano $F$, et al. Influenza and the rates of hospitalization for respiratory disease among infants and young children. $\mathrm{N}$ Engl J Med 2000;342(4):232-239.

21. Eickhoff TC, Sherman IL, Serfling RE. Observations on excess mortality associated with epidemic influenza. JAMA 1961;176: 776-782.

22. Luk J, Gross P, Thompson WW. Observations on mortality during the 1918 influenza pandemic. Clin Infect Dis 2001;33(8): 1375-1378.

23. Park M, Wu P, Goldstein E, Kim WJ, Cowling BJ. Influenza-associated excess mortality in South Korea. Am J Prev Med 2016; 50(4):e111-e119.

24. Nielsen J, Krause TG, Mølbak K, Influenza-associated mortality determined from all-cause mortality, Denmark 2010/11-2016/ 17: the FluMOMO model. Influenza Other Respir Viruses 2018; 12(5):591-604.

25. Yu X, Wang C, Chen T, Zhang W, Yu H, Shu Y, et al. Excess pneumonia and influenza mortality attributable to seasonal influenza in subtropical Shanghai, China. BMC Infect Dis 2017;17(1): 756.

26. Lytras T, Pantavou K, Mouratidou E, Tsiodras S. Mortality attributable to seasonal influenza in Greece, 2013 to 2017: variation by type/subtype and age, and a possible harvesting effect. Euro Surveill 2019;24(14):1800118.

27. Liu Z, Zhang J, Zhang Y, Lao J, Liu Y, Wang H, et al. Effects and interaction of meteorological factors on influenza: based on the surveillance data in Shaoyang, China. Environ Res 2019; 172:326-332.

28. Nunes B, Viboud C, Machado A, Ringholz C, Rebelo-de-Andrade $H$, Nogueira $P$, et al. Excess mortality associated with influenza epidemics in Portugal, 1980 to 2004. PLoS One 2011;6(6): e20661.

29. Hardelid P, Pebody R, Andrews N. Mortality caused by influenza and respiratory syncytial virus by age group in England and Wales 1999-2010. Influenza Other Respir Viruses 2013;7(1): 35-45.

30. Vestergaard LS, Nielsen J, Krause TG, Espenhain L, Tersago K, Bustos Sierra N, et al. Excess all-cause and influenza-attributable mortality in Europe, December 2016 to February 2017. Euro Surveill 2017;22(14):30506.

31. Zhou H, Thompson WW, Belongia EA, Fowlkes A, Baxter R, Jacobsen $S J$, et al. Estimated rates of influenza-associated outpatient visits during 2001-2010 in 6 US integrated healthcare delivery organizations. Influenza Other Respir Viruses 2018; 12(1):122-131.

32. Zhou H, Thompson WW, Viboud CG, Ringholz CM, Cheng PY, Steiner C, et al. Hospitalizations associated with influenza and respiratory syncytial virus in the United States, 1993-2008. Clin Infect Dis 2012;54(10):1427-1436.

33. Zhang H, Xiong Q, Wu P, Chen Y, Leung NH, Cowling BJ. Influenza-associated mortality in Yancheng, China, 2011-15. Influenza Other Respir Viruses 2018;12(1):98-103.

34. Thompson WW, Shay DK, Weintraub E, Brammer L, Bridges CB, Cox NJ, et al. Influenza-associated hospitalizations in the United States. JAMA 2004;292(11):1333-1340.

35. Thompson WW, Moore MR, Weintraub E, Cheng PY, Jin X, Bridges $C B$, et al. Estimating influenza-associated deaths in the United States. Am J Public Health 2009;99 Suppl 2:S225-S230.

36. Walter ND, Taylor TH, Shay DK, Thompson WW, Brammer L, Dowell SF, et al. Influenza circulation and the burden of invasive pneumococcal pneumonia during a non-pandemic period in the United States. Clin Infect Dis 2010;50(2):175-183.

37. Centers for Disease Control and Prevention. 2018 - 2019 U.S Flu season: preliminary burden estimates; 2019 May 9 [cited 2019 Aug 9]. Available from: https://www.cdc.gov/flu/about/ burden/preliminary-in-season-estimates.htm.

38. European Centre for Disease Prevention and Control. European Influenza Surveillance Network (EISN) [cited 2019 Aug 9]. Available from: https://ecdc.europa.eu/en/about-us/partnerships-and-networks/disease-and-laboratory-networks/eisn. 